\title{
EFFECT OF DELAYED MECHANICAL FEEDBACK ON LONG JUMP PERFORMANCE
}

original paper

() Wroclaw University of Health and Sport Sciences

DOI: https://doi.org/10.5114/hm.2022.108320

\section{UDAY CH. HASAN ${ }^{1 \oplus}$, ESAM ELDIN SHABAN HASAN ${ }^{2}$}

${ }^{1}$ Department of Physical Education and Sport Sciences, Al-Kitab University, Altun Kupri, Iraq

${ }^{2}$ Faculty of Physical Education, Assiut University, Assiut, Egypt

\section{ABSTRACT}

Purpose. The present study assesses the extent to which delayed mechanical feedback affects technical and numerical long jump performance.

Methods. The participants were 45 first-grade students from the Department of Physical Education of Umm Al-Qura University. They were randomly divided into 3 equal groups. The first experimental group used delayed mechanical feedback, the second experimental group applied fast visual feedback, and the control group received oral explanation and guidance of a teacher. The delayed mechanical feedback condition lasted for 6 weeks. Each week included 2 units, each lasting for 90 minutes.

Results. The educational programs had a significant main effect on technical and numerical long jump performance $(p<0.05)$, with a large effect size, as the percentage of improvement ranged 9.95-42.32\%. Also, the differences across the 3 groups were statistically significant in terms of their technical and numerical performance $(p<0.05)$, favouring the mechanical feedback group, except for the difference between the fast visual feedback and the teacher guidance groups.

Conclusions. The delayed mechanical feedback program had a more significant positive effect on technical and numerical long jump performance than the other 2 programs.

Key words: biomechanics, athletics, motion analysis, jumping

\section{Introduction}

The long jump is a track and field event and constitutes a regular part of the modern Olympic Games. In this event, athletes use their power and skills to jump as far as they can [1]. When performing a long jump, the athlete transforms the horizontal velocity of their centre of gravity from the moment they jump to a vertical velocity while minimizing losses in the speed they gained as they approached the jump line [2]. Teaching this mechanism requires an extensive understanding of its nature, principles, and requirements, as well as the proper application of its scientific bases. The performance depends on a mechanical basis and a vital kinetic start of the whole body while maintaining a high speed and the sum forces that result from jumping [3]. Also, the kinetic transfer should be fast and harmonized with the jump [4]. In this way, the jumper's centre of gravity is such that their speed becomes maximized during the jumping and takeoff phases [5].

As mentioned, the goal of a long jump event is to jump as far as the athlete can. A long jump trial includes 4 phases: approach (running), takeoff, flight, and landing. Some researchers have determined that the takeoff speed, takeoff angle, takeoff height, and aerodynamics are the 4 biomechanical parameters of the long jump that affect the flight distance $[6,7]$. Meanwhile, Bridgett and Linthorne [8] label the biomechanical principles of the long jump as the run-up, takeoff, flight, and landing phases. These principles underlie an athlete's success in long jump competitions.

Many investigators believe that most of the top numerical achievements in the long jump are due to exceptionally strong approaches and jumps [1, 9-11]. As such, most training programs focus on these 2 phases, as well as their connection to the takeoff phase. Bou-

Correspondence address: Uday CH. Hasan, Department of Physical Education and Sport Sciences, Al-Kitab University, P.O. Box: 1068, Altun Kupri 36015, Iraq, e-mail: dr_udayhasan@uoalkitab.edu.iq, https://orcid.org/0000-0002-5809-3743

Received: July 31, 2020

Accepted for publication: April 8, 2021

Citation: Hasan UCH, Hasan EES. Effect of delayed mechanical feedback on long jump performance. Hum Mov. 2022; 23(4):140-147; https://doi.org/10.5114/hm.2022.108320. 
chouras et al. [12] refer to this as mechanical variables during performance. Researchers have conducted kinematic analyses to identify errors or weaknesses that need to be overcome, consequently raising athletes' levels of achievement [13-15]. Other authors have identified kinematic principles that can be used to assess the development of performance in various aspects (sprint, angle of sprint, height of sprint point, height of landing, and height during the flight phase). These factors are affected during the jump as a mark of the athlete's advancement and capacity to use the effort that influences the distance of achievement. However, this depends on the individual kinematic features and conditions of each jumper under normal circumstances, which help athletes to achieve high scores $[16,17]$.

Contemporary long jump coaching methods include monitoring athletes during their performance and then suggesting actions for them to practise or reviewing slow-motion videos to analyse their movement while jumping [18-21]. For instance, Sethu [22] examined the effects of technique training with and without visual feedback on high jump performance. In the study, 24 university students were chosen and divided into 2 equal groups. The first group underwent technique training with visual feedback, while the second group received technique training without visual feedback; the training was performed 3 days a week for 6 weeks. The results revealed the outperformance of the technique training with visual feedback over the non-visual feedback one on the high jump. In another investigation, Durai [23] observed how visual feedback affected students' volleyball skills among 15 university volleyball players. The participants underwent skill training 3 days a week for 6 weeks. The skills that were focused on included service, passing, and spike. One significant outcome was a considerable improvement in the volleyball skills due to the effect of the visual feedback. Meanwhile, Anantharaj and Durai [24] studied the effects of skill training with and without video feedback on long jump performance; 12 university players participated in the skill training with video feedback, while 12 others underwent skill training without video feedback. The study implied that a significant skill training improvement occurred in the group with the video feedback compared with the other group. Manikandan [25] examined the effect of video modelling combined with video feedback on long jump techniques. For that purpose, the participants who were chosen received skill training with video modelling combined with video feedback. There was a significant improvement of explosive power, long jump performance, and long jump technique owing to the effect of skill training with video modelling and video feedback. So, feedback allows to consistently preserve a predetermined speed and therefore maintain the specified exercise intensity. This can result in a more effective execution of training goals and thereby boost training outcomes [26].

Still, not much is known about quantitative external feedback, especially in a mechanical sense. Therefore, the present study used mechanical feedback as an educational method to improve specific aspects of long jump performance. The study was also intended to compare the effectiveness of this method with that of other educational methods. The work is based on the principle that performance analysis is the primary means of reaching mechanical achievements by closely examining an athlete's performance. This is thought to be because it is difficult to evaluate performance errors with a naked eye [27]. Equipping the teacher with mechanical information about kinetics can raise the efficiency of the educational process, as the learner can be encouraged to think about the effects of their kinetic mechanical performance [20]. This, in turn, provides the athlete with the motivation, guidance, and support needed to improve their performance.

Therefore, mechanical feedback is undoubtedly important. It offers the learner mechanical information about their technical performance and ways to improve it through training. Continuously providing mechanical feedback helps an athlete to master their muscular nervous action mechanisms and, thus, achieve a higher level of performance [28].

In light of the above discussion, it was hypothesized that using delayed mechanical feedback would have a more substantial positive effect on athletes' long jump performance than fast visual feedback or oral explanations and guidance from coaches.

\section{Material and methods}

\section{Participants}

The participants were 45 first-grade students from the Department of Physical Education of Umm Al-Qura University during the 2018/2019 academic year (age: $19.28 \pm 1.16$ years, height: $174.66 \pm 5.37 \mathrm{~cm}$, body mass: $73.8 \pm 6.25 \mathrm{~kg}$, technical level: $62.66 \pm 8.57$ mark, numerical level: $4.47 \pm 0.5 \mathrm{~m}$ ). The subjects were randomly divided into 3 equal groups. The first experimental group used delayed mechanical feedback, the second experimental group applied fast visual feedback, and the control group received oral explanations and guidance from the teacher. All participants 
were informed of the study design and protocol prior to the study commencement. None of them reported having any previous injuries. There were no significant differences between the groups in terms of the technical or numerical levels before the educational programs were implemented $(p>0.05)$.

\section{Video camera}

A Sony video camera (numerical camera 8DCRTRV820E) with a frequency of 50 frames per second was used. The camera was placed beside the approach path on the same side as the participant's jumping leg, $10 \mathrm{~m}$ away from the jumping panel. The distance between the centre of the lens and the surface of the ground was $1.6 \mathrm{~m}$. The camera was set up so that it captured the participants' movements during the acceleration stage. Each participant was given 3 attempts; the best jump of each individual was analysed.

\section{Biomechanical variables}

The jumping and flight phases are crucial. Therefore, the biomechanical variables were defined in accordance with their contribution to achieving each athlete's typical distance. These biomechanical variables were maximum height during the flight phase, landing height $\left(\mathrm{h}_{1}\right)$, takeoff height $\left(\mathrm{h}_{0}\right)$, takeoff angle $\left(\alpha_{0}\right)$, and takeoff velocity $\left(\mathrm{V}_{0}\right)[15,29-31]$. These variables were used for mechanical feedback in the first experimental group in every teaching unit.

\section{Technical level assessment}

A technical level assessment form was designed; the included items referred to 4 technical phases (run-up, takeoff, flight, and landing). After modifications, the final version of the form comprised 22 statements totalling 100 marks.

To verify the reliability of the form, the researchers applied and re-applied the test. In this procedure, the technical performance of 15 students not involved in the ultimate study was assessed with the use of the form. The best of 3 long jump trials for each individual was evaluated technically by one referee. After 3 days, the same experimental procedure was applied so that a second technical assessment could be made. The correlation between the results of the first and second assessments $(r=0.92 ; \alpha \leq 0.05 ; n=15)$ confirmed the reliability of the form. Also, the researchers evaluated the validity of 5 referees. The results approved the assessment items by a value ranging $80-100 \%$.

\section{The proposed educational program}

The researchers designed an educational program that aimed to improve the participants' technical long jump performance. They reviewed relevant studies on track and field events in general and on long jumping in particular. In addition, the program was presented to a set of experts who were consulted with regard to the program principles concerning its reliability, the procedure for assessing its aims, and its suitability for the targeted group. The opinions and remarks of the experts were taken into consideration.

The program lasted for 6 weeks. Each week included 2 units, each lasting for 90 minutes. The program involved the following:

1. Determining the start and the end periods of the program.

2. Implementing the tests and assessments of technical and numerical performance to determine the athletes' performance levels.

3. Dividing the educational units into the following parts:

a) General and specific warm-ups, lasting for 25 minutes. These were intended to promote physical and psychological preparation and blood circulation. They consisted of a set of simple entertaining and preliminary actions.

b) The main part, lasting for 50 minutes: 20 minutes to apply delayed mechanical feedback for the first group, fast visual feedback for the second group, and teacher guidance for the third group. The exercises performed in the main part of the training unit developed the elasticity of the backbone and joints, the strength of the legs and back, the technical performance of the essential acceleration phase, the approaching speed, the takeoff force, the takeoff speed (using a typical angle), the maximum height of the flight phase, and the landing by extending the legs forward.

c) The cool-down phase, lasting for 15 minutes. It allowed the participants to reset their bodies to normal, relaxed conditions. This part involved a set of simple actions and exercises.

\section{Data analysis}

The statistical processing was performed with the Statistical Package for the Social Sciences (SPSS for Windows, version 22.0, IBM Corp., Armonk, NY, USA). The percentages were calculated. The analysis also involved means, standard deviations, skewness, the correlation coefficient, the paired sample $t$-test, one-way analysis of variance (ANOVA), and the least signifi- 
cant difference. Statistical significance was set at $p<$ 0.05 . Practical differences were assessed by calculating Cohen's $d$ effect size $(E S)$ [32, 33]. The magnitudes of the $t$-test results were labelled as follows [34]: 0.2-0.5 small, 0.5-0.8 - moderate, > 0.8 - large. For the oneway ANOVA, the labels were as follows: 0.01-0.06 small, 0.06-0.14 - moderate, > 0.14 - large. The variables distribution normality was verified with the Kolmogorov-Smirnov test.

\section{Ethical approval}

The research related to human use has complied with all the relevant national regulations and institutional policies, has followed the tenets of the Declaration of Helsinki, and has been approved by the Ethics Committee of the Umm Al-Qura University (Ref. No. 412; October 20, 2019).

\section{Informed consent}

Informed consent has been obtained from all individuals included in this study.

\section{Results}

The mean pre- and post-program technical and numerical levels of the experimental and control groups are included in Table 1. A significant main effect for the educational programs was found for the technical and numerical levels $(p<0.05)$. Large ES values were observed for differences in (i) the technical level between pre- and post-program assessments (mechanical, fast visual, and teacher guidance) (d: 8.237, 1.720, 1.410, respectively) and (ii) the numerical level between pre- and post-program assessments (mechanical, fast visual, and teacher guidance) ( $d: 5.913$, $4.895,3.000$, respectively), as the percentage of improvement ranged $9.95-42.32 \%$.

The one-way ANOVA was employed to determine whether any of the 3 educational programs had a more robust effect than the others on the participants' technical and numerical levels (Table 2). The ANOVA data included $F$-values of 6.25 for the technical level and 14.81 for the numerical level. These values indicate that there was a significant difference between the 3 educational programs $(p<0.05)$. Large $E S$ values were found for differences in (i) the technical level $(d=$ $0.546)$ and (ii) the numerical level $(d=0.840)$.

The least significant difference test (Table 3) was utilized to gather more details about the significant differences described in Table 2. The values of mean differences revealed that the differences were statistically significant among the 3 groups in terms of their technical and numerical levels $(p<0.05)$, favouring the mechanical feedback group, except for the differ-

Table 1. Technical and numerical long jump performance levels (mean \pm standard deviation, $t$ value, and percentage of improvement)

\begin{tabular}{lllcrrrrr}
\hline Variable & Group & Pre-program & Post-program & $t$ & $p$ & $\begin{array}{c}\text { Effect } \\
\text { size }\end{array}$ & $\begin{array}{c}\text { Magnitude } \\
\text { Improvement } \\
(\%)\end{array}$ \\
\hline Technical & Mechanical & $60.66 \pm 7.03$ & $86.33 \pm 6.93$ & $15.95^{* *}$ & $<0.001$ & 8.237 & Large & 42.32 \\
level & Fast visual & $64.66 \pm 7.18$ & $75.33 \pm 10.93$ & $3.33^{* *}$ & 0.005 & 1.720 & Large & 16.50 \\
(mark) & Teacher guidance & $62.66 \pm 10.99$ & $73.66 \pm 13.15$ & $2.73^{*}$ & 0.016 & 1.410 & Large & 17.56 \\
\hline Numerical & Mechanical & $4.45 \pm 0.41$ & $5.86 \pm 0.40$ & $11.45^{* *}$ & $<0.001$ & 5.913 & Large & 31.69 \\
level & Fast visual & $4.55 \pm 0.48$ & $5.49 \pm 0.57$ & $9.48^{* *}$ & $<0.001$ & 4.895 & Large & 20.66 \\
(m) & Teacher guidance & $4.42 \pm 0.60$ & $4.86 \pm 0.53$ & $5.81^{* *}<0.001$ & 3.000 & Large & 9.95 \\
\hline
\end{tabular}

Significant difference between pre- and post-program assessments in the groups: ${ }^{*} p<0.01,{ }^{*} p<0.05$

Table 2. Results of the one-way analysis of variance of the study variables for the 3 groups in the post-program measurement

\begin{tabular}{|c|c|c|c|c|c|c|c|c|}
\hline Variable & Source of variance & $\begin{array}{l}\text { Sum of } \\
\text { squares }\end{array}$ & $d f$ & Mean square & $F$ & $p$ & $\begin{array}{l}\text { Effect } \\
\text { size }\end{array}$ & Magnitude \\
\hline \multirow{3}{*}{ Technical level (mark) } & Between groups & 1421.11 & 2 & 710.55 & & & & \\
\hline & Within groups & 4770 & 42 & 113.57 & $6.25^{*}$ & 0.004 & 0.546 & Large \\
\hline & Total & 6191.11 & 44 & & & & & \\
\hline \multirow{3}{*}{ Numerical level (m) } & Between groups & 7.67 & 2 & 3.83 & & & & \\
\hline & Within groups & 10.87 & 42 & 0.25 & $14.81 *$ & $<0.001$ & 0.840 & Large \\
\hline & Total & 18.54 & 44 & & & & & \\
\hline
\end{tabular}

Significant difference between groups: ${ }^{*} p<0.01$ 
U.CH. Hasan, E.E.S. Hasan, Effect of mechanical feedback on long jump

Table 3. Results of the least significant difference test to identify the sources of differences in the technical and numerical levels of the 3 groups

\begin{tabular}{|c|c|c|c|c|c|c|}
\hline Variable & Group 1 & Group 2 & $\begin{array}{l}\text { Mean difference } \\
\qquad(1-2)\end{array}$ & $p$ & Effect size & Magnitude \\
\hline \multirow{3}{*}{ Technical level (mark) } & Mechanical & Fast visual & 6.93 & $0.010 * *$ & 0.757 & Moderate \\
\hline & & Teacher guidance & 10.93 & $0.020 *$ & 1.040 & Large \\
\hline & Fast visual & Teacher guidance & 13.15 & 0.670 & - & - \\
\hline \multirow{3}{*}{ Numerical level (m) } & Mechanical & Fast visual & 0.40 & $0.050 *$ & 0.812 & Large \\
\hline & & Teacher guidance & 0.57 & $<0.001 * *$ & 1.214 & Large \\
\hline & Fast visual & Teacher guidance & 0.53 & $0.010 * *$ & 0.963 & Large \\
\hline
\end{tabular}

Significant difference between groups: ${ }^{*} p<0.01,{ }^{*} p<0.05$; '-’ stands for no significant difference

ence between the fast visual feedback group and the teacher guidance and explanation group $(p>0.05)$. Moderate $E S$ values were found for the differences between the mechanical feedback group's and the fast visual feedback group's technical levels $(d=0.757)$. A large $E S$ was observed for the technical level difference between the mechanical feedback and the teacher guidance groups $(d=1.040)$. Large $E S$ values were indicated for the following numerical level differences: (i) between the mechanical feedback and the fast visual feedback groups $(d=0.812)$, (ii) between the mechanical feedback and the teacher guidance groups $(d=$ 1.214), and (iii) between the fast visual feedback and the teacher guidance groups $(d=0.963)$.

\section{Discussion}

The educational programs had a significant main effect on technical and numerical long jump performance $(p<0.05)$, with a large $E S$, as the percentage of improvement ranged $9.95-42.32 \%$. Also, the differences across the 3 groups were statistically significant in terms of their technical and numerical performance $(p<0.05)$, favouring the mechanical feedback group, except for the difference between the fast visual feedback and the teacher guidance groups. All that can be interpreted to the jumper in the form of information that turns out beneficial during the performance and can be developed during learning focused on the suitable mechanical variables of the performance. The continuous provision of this information can promote mastery of neuromuscular function mechanisms, thus leading to the excellent synchronization of performance [35].

Tidow [36] concluded that continuously using assessment processes via mechanical systems was essential for ensuring that accurate scientific measurements affected the progress of performance, whereby the assessment depended on direct measurements. Without this measurement, the assessment process would be impossible, and without the assessment, there would be no feedback. Without the feedback, there would be no information about the results, and without this information, performance would not improve.

McCosker et al. [37] described the associations between the various aspects of competitive performance. Specifically, they noted that each jump should be considered part of a complex system of connected performance events that lead to competitive outcomes. Therefore, key indicators that refer to the desired performance should be used to simplify feedback data [38].

Statistically significant differences were also found between the pre- and post-program measurements within the fast visual feedback group. Providing feedback enables the learner to improve their performance through comparisons with a specific performance standard. This, in turn, helps them recognize how much they have progressed while identifying their weaknesses [20]. Bowtell et al. [39] implied that a learner's awareness of their progress led to performance improvements, while an absence of this awareness could delay learning. Their study reveals that understanding one's own results is a type of feedback that enables an athlete to progress in both the educational and technical sense. It has also been mentioned that presenting feedback to learners has a profound positive effect on them, and the importance of that increases in the beginners, who can learn kinematic skills faster as they continue training to achieve their desired results. This kind of feedback also boosts the learner's motivation and guides focusing their energy on learning new information while enhancing and reinforcing previously acquired knowledge; eventually, their level of performance is raised as a result of the improved educational skills [40-43]. 
Furthermore, there were statistically significant differences between the pre- and post-program measurements within the control group (oral interpretation and teacher guidance). Education reflects a mutual interaction between the teacher and the learner, the goal of which is for the learner to acquire desired knowledge and skills.

Statistically significant differences were observed among the 3 groups in terms of their technical and numerical performance levels, except for the difference between the technical performance of the fast visual feedback group and the control group. The researchers propose that feedback as such is a vital part of long jump athletes' education about their performance. The type of feedback offered should depend on the kinematic principles that are fundamental to technical performance for all phases of a jump. This kind of feedback provides the learner with essential information regarding, for example, their performance efficiency during or after a competition (or at both points) [44]. Also, the information relayed to the learner can be strengthened, errors can be corrected, and misunderstandings and misconceptions can be removed. This will enable the athlete to perform more confidently, thus encouraging them to increase their focus on reaching their goals [22].

If the teacher has a mechanical database that they can use to assess physical performance, they can conceive the basic components of strong technical performance. When the teacher is equipped with mechanical knowledge, it is easier for them to set useful objectives on the basis of the athlete's actions [45, 46]. Mechanical analyses help practitioners to explore minute errors and determine how to fix them. The aim of analysing physical performance is to consider the various aspects of performance from a mechanical perspective because physical performance follows mechanical rules and principles [7, 47].

Schmidt et al. [48] consider feedback to be a crucial factor in learning and enhancing athletes' skills in many sports. In all its forms, the feedback that precedes, accompanies, and follows performance impacts on the learning process and boosts performance. Feedback continuously accompanies all steps of learning. Becerra Motta and Becker [49] showed that feedback related to mechanical variables raised overall athletic performance as well as several specific physical variables reflected in an athlete's performance. Developing the mechanical variables can profit from educational programs to raise the technical level, which affects the numerical achievement level.
This study included some limitations, such as the restriction of the sample to one university. As it is known, $2 \mathrm{D}$ analysis is the basis for evaluating activities and sports skills. However, one cannot claim that 2D analysis can describe the whole body movement without losing some important characteristics in the long jump. Therefore, a sample from several universities needs to be included besides conducting more studies using other technologies, such as 3D analysis or a force platform. In spite of that, this study, to our knowledge, is a pioneer in using the delayed mechanical feedback in the long jump. Thus, it offers useful information related to providing the learner or the trainee with mechanical feedback about the results of the movement and its impact on increasing the educational process efficiency in terms of directing the learner's efforts towards thinking about the outcome of their movement mechanical performance. This is a source of motivation, direction, and support to develop performance that achieves the optimum technical and numerical level in the long jump competition.

Some practical implications may also arise from the study. One of them is the need for accurate feedback that depends on the technologies. This is in addition to the fact that the study included a longer educational intervention using the delayed mechanical feedback method rather than comparisons between 2 short-term trials. Accordingly, we recommend the application of delayed mechanical feedback in teaching the long jump race in particular, and field and track competitions in general, and the use of different types of feedback in similar studies in teaching field and track competitions. We also advise athletics trainers and teachers to adopt the necessary mechanical foundations and laws in the training and teaching process of athletes and students.

\section{Conclusions}

The educational program based on delayed mechanical feedback improved long jump athletes' technical and numerical performance to a significantly greater extent than the programs that employed fast visual feedback or teacher explanations and guidance. The positive effect of delayed technical feedback on technical and numerical long jump performance was stronger than that of fast visual feedback and a normal training program.

\section{Acknowledgements}

We gratefully acknowledge the support of the participants, who were essential to the success of this research. 


\section{Disclosure statement}

No author has any financial interest or received any financial benefit from this research.

\section{Conflict of interest}

The authors state no conflict of interest.

\section{References}

1. Kamnardsiri T, Janchai W, Khuwuthyakorn P, Suwansrikham P, Klaphajone J, Suriyachan P. Knowledge-based system framework for training long jump athletes using action recognition. J Adv Inf Technol. 2015;6(4):182-193; doi: 10.12720/jait.6.4.182-193.

2. Fattah OA, Bataineh AS. Analysis of kinematics of the approach run in long jump event among Jordanian male team. Russ J Biomech. 2020;24(1):15-22; doi: 10.15593/ RJBiomech/2020.1.02.

3. Theodorou AS, Panoutsakopoulos V, Exell TA, Argeitaki P, Paradisis GP, Smirniotou A. Step characteristic interaction and asymmetry during the approach phase in long jump. J Sports Sci. 2017;35(4):346-354; doi: 10.1080/02640414.2016.1164884.

4. Panteli FN, Theodorou A, Pilianidis T, Smirniotou A. Locomotor control in the long jump approach run in young novice athletes. J Sports Sci. 2014;32(2):149-156; doi: 10.1080/02640414.2013.810344.

5. Graham-Smith P, Lees A. A three-dimensional kinematic analysis of the long jump take-off. J Sports Sci. 2005; 23(9):891-903; doi: 10.1080/02640410400022169.

6. Pan Z. Analysis of mechanical model on factors influencing the long jump result under the perfect condition. Res J Appl Sci Eng Technol. 2013;5(5):1589-1593; doi: 10.19026/rjaset.5.4909.

7. Bartlett R. Introduction to sports biomechanics: analysing human movement patterns. Abingdon: Routledge; 2014.

8. Bridgett LA, Linthorne NP. Changes in long jump takeoff technique with increasing run-up speed. J Sports Sci. 2006;24(8):889-897; doi: 10.1080/02640410500 298040.

9. Guiman MV. Theoretical and experimental aspects concerning the long jump trial. Bull Transilv Univ Bras I Eng Sci. 2015;8(57):17-24.

10. Makaruk H, Starzak M, Sadowski J. Does step length adjustment determine take-off accuracy and approach run velocity in long and triple jumps? Hum Mov. 2015;16(3):124-129; doi: 10.1515/humo-20150038.

11. Guiman MV. The take-off angle analysis in case of long jump trial. In: ICMS 2019 \& COMEC 2019. Brasov: Transilvania University of Brasov; 2019; 50-53.

12. Bouchouras G, Moscha D, Papaiakovou G, Nikodelis T, Kollias I. Angular momentum and landing efficiency in the long jump. Eur J Sport Sci. 2009;9(1):53-59; doi: 10.1080/17461390802594243.
13. Hraski M, Hraski Ž, Mrakovi S, Horvat V. Relation between anthropometric characteristics and kinematic parameters which influence standing long jump efficiency in boys and adolescents. Coll Antropol. 2015; 39(Suppl. 1):47-55.

14. Fernandez-Santos JR, Gonzalez-Montesinos JL, Ruiz JR, Jiménez-Pavón D, Castro-Piñero J. Kinematic analysis of the standing long jump in children 6- to 12-yearsold. Meas Phys Educ Exerc Sci. 2018;22(1):70-78; doi: 10.1080/1091367X.2017.1383913.

15. Pavlovic R, Bonacin D, Stankovic D. Differences in kinematic parameters of the long jump between male and female finalists of World Championships - Berlin 2009. Int J Sci Cult Sport. 2016;4(4):353-366; doi: 10.14486/IntJSCS528.

16. Nolan L, Lees A. The influence of lower limb amputation level on the approach in the amputee long jump. J Sports Sci. 2007;25(4):393-401; doi: 10.1080/02640 410600717931.

17. Mishra MK, Rathore VS. Speed and agility as predictors of long jump performance of male athletes. Turk J SportExerc. 2016;18(2):27-33; doi: 10.15314/tjse.40102.

18. Palao JM, Hastie PA, Guerrero Cruz P, Ortega E. The impact of video technology on student performance in physical education. Technol Pedagog Educ. 2015; 24(1):51-63; doi: 10.1080/1475939X.2013.813404.

19. O’Donoghue P. The use of feedback videos in sport. Int J Perform Anal Sport. 2006;6(2):1-14; doi: 10.1080/ 24748668.2006.11868368.

20. Potdevin F, Vors O, Huchez A, Lamour M, Davids K, Schnitzler C. How can video feedback be used in physical education to support novice learning in gymnastics? Effects on motor learning, self-assessment and motivation. Phys Educ Sport Pedagog. 2018;23(6):559-574; doi: 10.1080/17408989.2018.1485138.

21. Ningthoujam R. Construction and importance of video based analyses teaching in physical education by use of window live movie maker. Video J Educ Pedagog. 2016;1(1):4; doi: 10.1186/s40990-016-0003-2.

22. Sethu S. Effect of technique training with and without visual feedback on high jump performance. Int $\mathrm{J}$ Emerg Technol Comput Appl Sci. 2014;10(4):314-318.

23. Durai C. Effect of visual feedback on volleyball skills among physical education students. Int J Creat Res Thoughts. 2016;4(2):409-412.

24. Anantharaj G, Durai C. Effect of skill training with and without video feedback on long jump performance. Int J Adv Res Innov Ideas Educ. 2018;4(1):552-556.

25. Manikandan P. Impact of video modelling with video feedback on long jump skills. Res Rev Int J Multidiscip. 2019;4(4):497-499.

26. Szczepan S, Zaton K, Borkowski J. The effects of concurrent visual feedback on the control of swimming intensities above the onset of blood lactate accumulation. Hum Mov. 2018;19(4):49-55; doi: 10.5114/hm.2018. 77324. 
27. Aginsky KD, Noakes TD. Why it is difficult to detect an illegally bowled cricket delivery with either the naked eye or usual two-dimensional video analysis. Br J Sports Med. 2010;44(6):420-425; doi: 10.1136/bjsm. 2008.047266.

28. Magill R, Anderson D. Motor learning and control: concepts and applications, $11^{\text {th }}$ ed. New York: McGraw Hill Education; 2017.

29. Campos J, Gàmez J, Encarnación A, Gutiérrez-Dávila M, Rojas J, Wallace ES. Three-dimensional kinematics during the take-off phase in competitive long jumping. Int J Sports Sci Coach. 2013;8(2):395-406; doi: 10.1260/1747-9541.8.2.395.

30. Akl A-R. Biomechanical study to assess the variations between male and female in long jump. Sport Sci Pract Asp. 2014;11(1):33-36.

31. Guiman MV, Ioan B. A method for the analysis of the take-off and the flight start in the long jump. Palestrica Third Millenn Civiliz Sport. 2015;16(4):324-328.

32. Cohen J. Statistical power analysis for the behavioral sciences, $2^{\text {nd }}$ ed. New York: Routledge; 2013.

33. Lakens D. Calculating and reporting effect sizes to facilitate cumulative science: a practical primer for ttests and ANOVAs. Front Psychol. 2013;4:863; doi: 10.3389/fpsyg.2013.00863.

34. Batterham AM, Hopkins WG. Making meaningful inferences about magnitudes. Int J Sports Physiol Perform. 2006;1(1):50-57; doi: 10.1123/ijspp.1.1.50.

35. Scott SH, Cluff T, Lowrey CR, Takei T. Feedback control during voluntary motor actions. Curr Opin Neurobiol. 2015;33:85-94; doi: 10.1016/j.conb.2015.03. 006.

36. Tidow G. On the reproducibility of acyclic velocity maxima as a function of resistance magnitude and infraserial pause duration [in German]. In: Krug J, Minow H-J (eds.), Sports performance and training [in German]. Leipzig: Academia; 1995; 275-283.

37. McCosker C, Renshaw I, Greenwood D, Davids K, Gosden E. How performance analysis of elite long jumping can inform representative training design through identification of key constraints on competitive behaviours. Eur J Sport Sci. 2019;19(7):913-921; doi: 10.1080/17461391.2018.1564797.

38. Muniz PE. Detection of launch frame in long jump videos using computer vision and discreet computation. Bachelor thesis. Cambridge: Massachusetts Institute of Technology; 2019.

39. Bowtell MV, Tan H, Wilson AM. The consistency of maximum running speed measurements in humans using a feedback-controlled treadmill, and a comparison with maximum attainable speed during overground locomotion. J Biomech. 2009;42(15):2569-2574; doi: 10.1016/j.jbiomech.2009.07.024.

40. Jennings CT, Reaburn P, Rynne SB. The effect of a self-modelling video intervention on motor skill acquisition and retention of a novice track cyclist's stand- ing start performance. Int J Sports Sci Coach. 2013; 8(3):467-480; doi: 10.1260/1747-9541.8.3.467.

41. Perreault ME, French KE. External-focus feedback benefits free-throw learning in children. Res Q Exerc Sport. 2015;86(4):422-427; doi: 10.1080/02701367. 2015.1051613.

42. Zatoń K, Cześniewicz I, Szczepan S. Effects of verbal feedback on movement efficiency during swimming ergometry. Pol J Sport Tourism. 2018;25(3):5-9; doi: 10.2478/pjst-2018-0013.

43. Chatzopoulos D, Foka E, Doganis G, Lykesas G, Nikodelis T. Effects of analogy learning on locomotor skills and balance of preschool children. Early Child Dev Care. 2022;192(1):103-111; doi: 10.1080/03004 430.2020.1739029.

44. Sweigart CA, Collins LW, Evanovich LL, Cook SC. An evaluation of the evidence base for performance feedback to improve teacher praise using CEC's quality indicators. Educ Treat Child. 2016;39(4):419-444; doi: 10.1353/etc.2016.0019.

45. Glazier PS. Game, set and match? Substantive issues and future directions in performance analysis. Sports Med. 2010;40(8):625-634; doi: 10.2165/11534970000000000-00000.

46. Jeraj D, Veit J, Heinen T, Raab M. How do gymnastics coaches provide movement feedback in training? Int J Sports Sci Coach. 2015;10(6):1015-1024; doi: 10.1260/ 1747-9541.10.6.1015.

47. Szerdiova L, Simsik D, Dolna Z. Standing long jump and study of movement dynamics using human motion analysis. In: 2010 IEEE $8^{\text {th }}$ International Symposium on Applied Machine Intelligence and Informatics (SAMI). IEEE; 2010; 263-266. Available from: http:// ieeexplore.ieee.org/document/5423724/.

48. Schmidt RA, Lee TD, Winstein CJ, Wulf G, Zelaznik HN. Motor control and learning: a behavioral emphasis, $6^{\text {th }}$ ed. Champaign: Human Kinetics; 2018.

49. Becerra Motta JA, Becker RR. The effectiveness of biomechanical stimulation (BMS) in conjunction with traditional methods of strength endurance development in swimming [in German]. Leistungssport. 2001; 31(2):29-35. 